\title{
Efficacy of Irinotecan as Third-line Chemotherapy for Unresectable or Recurrent Gastric Cancer
}

\author{
MINORU FUKUCHI, KOHKI KUWABARA, TORU ISHIGURO, YOUICHI KUMAGAI, \\ KEIICHIRO ISHIBASHI, ERITO MOCHIKI and HIDEYUKI ISHIDA \\ Department of Digestive Tract and General Surgery, Saitama Medical Center, \\ Saitama Medical University, Kawagoe, Japan
}

\begin{abstract}
Aim: To evaluate the efficacy and safety of thirdline chemotherapy (CTX) for patients with unresectable or recurrent gastric cancer $(G C)$ refractory to $S-1$ with or without platinum and taxanes. Patients and Methods: We retrospectively analyzed clinicopathological and survival data of 26 patients who underwent third-line CTx. Results: Irinotecan therapy (odds ratio $=0.12,95 \%$ confidence interval $=0.02-0.38 ; p<0.01)$ and $\geq 2$ cycles of third-line CTx (odds ratio $=0.01,95 \%$ confidence intervaI $=0.01-0.11 ; p<0.01$ ) were independent predictors of longer progression-free survival in multivariate Cox regression analysis. In 18 patients (69\%) receiving irinotecan, the overall response rate was $11 \%$, and the disease control rate was 44\%. Median progression-free and overall survival were 3.5 and 11.3 months, respectively. Ten patients (56\%) had grade 3-4 toxicities, which were managed. Conclusion: Irinotecan therapy may become optimal and tolerated in the third-line setting to prolong progression-free survival by increasing the number of treatment cycles.
\end{abstract}

Gastric cancer (GC) is the third leading cause of cancer death worldwide, and it remains the second leading cause of cancer death in Japan (1). Generally, patients with unresectable or recurrent GC have poor prognosis and are treated with chemotherapy (CTx). In Japan, the SPIRITS trial, a phase-III study, established S-1 plus cisplatin as a standard first-line CTx regimen for unresectable or recurrent GC (2). Several phase-III studies showed a survival benefit with irinotecan or

This article is freely accessible online.

Correspondence to: Minoru Fukuchi, MD, Department of Digestive Tract and General Surgery, Saitama Medical Center, Saitama Medical University, 1981 Kamoda, Kawagoe, Saitama 350-8550, Japan. Tel: +81 492283619, Fax: +81 492228865, e-mail: mfukuchi@saitama-med.ac.jp

Key Words: Gastric cancer, irinotecan, third-line chemotherapy, progression-free survival. docetaxel as second-line CTx compared with best supportive care (3-5). In Japan, paclitaxel is commonly used as secondline CTx for unresectable or recurrent GC, and has provided overall response rates (ORR) of 16-24\%, median overall survival (OS) of 5-6 months, and modest toxicity in several phase-II studies (6-8). Moreover, nanoparticle albumin-bound (nab)-paclitaxel is also reported to be an option for secondline CTx, with an ORR of 24-28\% and median OS of 9-10 months, comparable to the efficacy of paclitaxel $(9,10)$.

In the phase-III WJOG4007 trial that compared weekly paclitaxel with irinotecan as second-line CTx for patients with advanced GC refractory to fluoropyrimidines plus platinum, OS did not differ between the two groups (11). Furthermore, in the recent phase-III RAINBOW trial, ramucirumab plus paclitaxel significantly improved OS compared with placebo plus paclitaxel in patients with advanced GC refractory to fluoropyrimidines plus platinum (12). This regimen has been regarded as the new standard second-line CTx for these patients.

Third-line CTx of advanced GC is expected to be developed in the near future. Therefore, it is important to evaluate the survival benefit of third-line CTx. After the WJOG4007 (11) and the RAINBOW (12) trials, taxanes are used as second-line CTx, and irinotecan more often as thirdline CTx in Japanese clinical practice. Moreover, each of four types of CTx, fluoropyrimidines, platinum, taxanes and irinotecan, were independently associated with longer OS in patients with advanced GC (13). However, there have been few reports on the efficacy and safety of irinotecan in the third-line setting for patients with advanced GC refractory to the other three types of CTx $(14,15)$. In this study, we retrospectively evaluated the efficacy and safety of irinotecan, compared with other agents, for patients with unresectable or recurrent GC refractory or those intolerant to S-1 with or without platinum and subsequent taxane therapy.

\section{Patients and Methods}

Patients. We retrospectively reviewed a database of 26 patients who had unresectable or recurrent GC refractory or were intolerant to S- 
1 with or without platinum and taxanes who underwent third-line CTx with irinotecan or other agents at Saitama Medical Center of Saitama Medical University from September 2012 to January 2017. We evaluated the efficacy and safety of irinotecan monotherapy and the outcomes compared with other agents in these 26 patients. This retrospective study was approved by the local Ethics Committee of Saitama Medical Center of Saitama Medical University (no. 613-III).

Tumor classification and histopathological grading were performed according to the Union for International Cancer Control pTNM staging guidelines, seventh edition (16). Terminology defined by the Japanese Gastric Cancer Association was used to avoid unnecessary confusion (17). All patients had at least one proven lesion with any noncurative factor such as peritoneal (P1), hepatic (H1) and distant metastasis (M1). Additionally, eligible patients were required to have an Eastern Cooperative Oncology Group performance status (ECOG PS) of 0-2.

Chemotherapy schedule. Patients received intravenous infusion of irinotecan $\left(100 \mathrm{mg} / \mathrm{m}^{2}\right)$ during a 90 -minute period weekly for 3 weeks followed by 1 week's rest (18). Treatment was discontinued at onset of disease progression, development of severe toxic effects, or the patient's request. Dose reduction or treatment delays were dependent on the toxicity or each physician's discretion in any course. Tumor response was objectively assessed after each treatment course according to the Response Evaluation Criteria in Solid Tumors (19). Adverse events were evaluated by the Common Terminology Criteria for Adverse Events, version 4.0 (20).

Follow-up schedule. Disease progression and development of new lesions were evaluated as needed by computed tomography. Carcinoembryonic antigen and cancer antigen 19-9 as tumor markers were measured every 4 weeks during treatment. Responses were evaluated every 8 weeks or earlier in patients with evidence of treatment failure. Physical examinations and laboratory tests were performed every week or 2 weeks during treatment.

Statistical analysis. Continuous variables are expressed as medians and ranges. Grouping of categorical and continuous variables was carried out using standard thresholds. Cox proportional hazard regression analysis was used to identify significant independent factors for progression-free survival (PFS). Factors with differences at $p<0.05$ according to univariate analysis were assessed by multivariate analysis. In the univariate and multivariate analyses, odds ratios (ORs) with 95\% confidence intervals (CIs) were calculated. All statistical analyses were performed with JMP 5.0 software (SAS Institute, Cary, NC, USA). Values of $p<0.05$ were considered significant.

\section{Results}

Patient characteristics. Characteristics of the 26 patients who underwent third-line CT are presented in Table I. These patients included 19 men and seven women with a median age of 65 years (range=33-75 years). Of the 26 patients, 16 $(62 \%)$ underwent gastrectomy. The median serum albumin level was 3.7 (range=2.2-4.4) $\mathrm{g} / \mathrm{dl}$ on initial induction of third-line CTx. The median time from first- to third-line CTx and of second-line CTx was 15 (range=6.1-64) and 2.6 (range $=0.7-25)$ months, respectively.
Table I. Characteristics of 26 patients with unresectable or recurrent gastric cancer receiving third-line chemotherapy.

\begin{tabular}{|c|c|c|}
\hline \multicolumn{3}{|l|}{ Characteristic } \\
\hline Age, years & Median (range) & $62(33-75)$ \\
\hline \multirow[t]{2}{*}{ Gender, $\mathrm{n}$} & Male & 19 \\
\hline & Female & 7 \\
\hline \multirow[t]{3}{*}{ Performance status, $\mathrm{n}$} & 0 & 9 \\
\hline & 1 & 8 \\
\hline & 2 & 9 \\
\hline \multirow[t]{3}{*}{ Location, $\mathrm{n}$} & Upper & 11 \\
\hline & Middle & 3 \\
\hline & Lower & 12 \\
\hline \multirow[t]{3}{*}{ Histological grade, $\mathrm{n}$} & 1 & 2 \\
\hline & 2 & 6 \\
\hline & 3 & 18 \\
\hline \multirow[t]{2}{*}{ Primary lesion, $\mathrm{n}$} & Absent & 16 \\
\hline & Present & 10 \\
\hline \multirow[t]{2}{*}{ Peritoneal metastasis $(\mathrm{P}), \mathrm{n}$} & 0 & 15 \\
\hline & 1 & 11 \\
\hline \multirow[t]{2}{*}{ Hepatic metastasis $(\mathrm{H}), \mathrm{n}$} & 0 & 20 \\
\hline & 1 & 6 \\
\hline \multirow[t]{2}{*}{ Distant metastasis $(\mathrm{M}), \mathrm{n}$} & 0 & 12 \\
\hline & 1 & 14 \\
\hline \multirow{3}{*}{$\begin{array}{l}\text { Number of noncurative } \\
\text { factors, } \mathrm{n}\end{array}$} & 1 & 20 \\
\hline & 2 & 4 \\
\hline & 3 & 2 \\
\hline \multirow{5}{*}{$\begin{array}{l}\text { Organs of noncurative } \\
\text { factor, } \mathrm{n}\end{array}$} & Peritoneum & 15 \\
\hline & Liver & 6 \\
\hline & Lung & 4 \\
\hline & Lymph node & 6 \\
\hline & Other & 2 \\
\hline $\begin{array}{l}\text { Median number of } \\
\text { cycles (range) }\end{array}$ & Median (range) & $2(1-17)$ \\
\hline $\begin{array}{l}\text { Relative dose intensity } \\
\text { (range), } \%\end{array}$ & Median (range) & $81(24-100)$ \\
\hline \multirow[t]{4}{*}{ First-line CTx, $\mathrm{n}$} & S-1 & 5 \\
\hline & S-1+cisplatin & 18 \\
\hline & S-1+paclitaxel & 1 \\
\hline & S-1+oxaliplatin & 2 \\
\hline \multirow[t]{6}{*}{ Second-line CTx, $\mathrm{n}$} & Paclitaxel & 1 \\
\hline & Docetaxel & 1 \\
\hline & Nab-paclitaxel & 17 \\
\hline & S-1+paclitaxel & 3 \\
\hline & S-1+docetaxel & 1 \\
\hline & Ramucirumab+paclitaxel & 3 \\
\hline \multirow[t]{5}{*}{ Third-line CTx, $\mathrm{n}$} & Irinotecan & 18 \\
\hline & Docetaxel & 3 \\
\hline & Nab-paclitaxel & 3 \\
\hline & S-1+oxaliplatin & 1 \\
\hline & Capecitabine+oxaliplatin & 1 \\
\hline \multirow[t]{4}{*}{ Toxicity grade, $\mathrm{n}$} & 1 & 3 \\
\hline & 2 & 7 \\
\hline & 3 & 7 \\
\hline & 4 & 9 \\
\hline
\end{tabular}

Nab: Nanoparticle albumin-bound; CTx: chemotherapy. *Overlapping cases. 
Table II. Univariate and multivariate predictors of progression-free survival in 26 patients with unresectable or recurrent gastric cancer receiving third-line chemotherapy.

\begin{tabular}{|c|c|c|c|c|c|c|}
\hline \multirow[t]{2}{*}{ Variable } & \multirow[b]{2}{*}{ Subgroup } & \multirow[b]{2}{*}{$\mathrm{n}$} & \multicolumn{2}{|c|}{ Univariate } & \multicolumn{2}{|c|}{ Multivariate } \\
\hline & & & OR $(95 \% \mathrm{CI})$ & $p$-Value & OR $(95 \% \mathrm{CI})$ & $p$-Value \\
\hline \multirow{2}{*}{ Age, years } & $<62$ & 13 & 1 & & & \\
\hline & $\geq 62$ & 13 & $0.93(0.40-2.13)$ & 0.86 & & \\
\hline \multirow[t]{2}{*}{ Gender } & Male & 19 & $0.49(0.19-1.42)$ & 0.18 & & \\
\hline & Female & 7 & 1 & & & \\
\hline \multirow[t]{2}{*}{ Performance status } & 0,1 & 17 & $0.54(0.33-0.87)$ & 0.01 & 1 & \\
\hline & 2 & 9 & 1 & & $0.56(015-2.03)$ & 0.37 \\
\hline \multirow{2}{*}{ Location } & Upper & 11 & 1 & & & \\
\hline & Middle, Lower & 15 & $0.71(0.44-1.12)$ & 0.14 & & \\
\hline \multirow[t]{2}{*}{ Histological grade } & 1,2 & 8 & $0.75(0.44-1.18)$ & 0.22 & & \\
\hline & 3 & 18 & 1 & & & \\
\hline \multirow{2}{*}{ Primary lesion } & Absent & 16 & $0.73(0.48-1.12)$ & 0.15 & & \\
\hline & Present & 10 & 1 & & & \\
\hline \multirow[t]{2}{*}{ Peritoneal metastasis } & $\mathrm{P} 0$ & 15 & $0.55(0.34-0.87)$ & 0.01 & $0.74(0.40-1.32)$ & 0.31 \\
\hline & $\mathrm{P} 1$ & 11 & 1 & & 1 & \\
\hline \multirow[t]{2}{*}{ Hepatic metastasis } & $\mathrm{H} 0$ & 20 & 1 & & & \\
\hline & $\mathrm{H} 1$ & 6 & $0.60(0.20-1.52)$ & 0.3 & & \\
\hline \multirow[t]{2}{*}{ Distant metastasis } & M0 & 12 & 1 & & & \\
\hline & M1 & 14 & $0.82(0.36-1.89)$ & 0.63 & & \\
\hline \multirow{2}{*}{ No. of noncurative factors } & 1 & 20 & $0.91(0.58-1.52)$ & 0.07 & & \\
\hline & 2,3 & 6 & 1 & & & \\
\hline \multirow[t]{2}{*}{ Third-line CTx } & Irinotecan & 18 & $0.20(0.08-0.42)$ & $<0.01$ & $0.12(0.02-0.38)$ & $<0.01$ \\
\hline & Non-irinotecan & 8 & 1 & & 1 & \\
\hline \multirow[t]{2}{*}{ No. of cycles } & $<2$ & 14 & 1 & & 1 & \\
\hline & $\geq 2$ & 12 & $0.03(0.01-0.16)$ & $<0.01$ & $0.01(0.01-0.11)$ & $<0.01$ \\
\hline \multirow[t]{2}{*}{ Relative dose intensity } & $<81 \%$ & 13 & $0.93(0.61-1.41)$ & 0.73 & & \\
\hline & $\geq 81 \%$ & 13 & 1 & & & \\
\hline \multirow{2}{*}{ Toxicity grade } & 1,2 & 11 & $0.79(0.50-1.20)$ & 0.28 & & \\
\hline & 3,4 & 15 & 1 & & & \\
\hline \multirow[t]{2}{*}{ Serum albumin, g/dl } & $<3.7$ & 12 & 1 & & & \\
\hline & $\geq 3.7$ & 14 & $0.39(0.17-0.91)$ & 0.03 & $0.72(0.33-1.38)$ & 0.34 \\
\hline \multirow{2}{*}{ Time from first- to third-line CTx, months } & $<15$ & 13 & $0.93(0.60-1.44)$ & 0.75 & & \\
\hline & $\geq 15$ & 13 & 1 & & & \\
\hline \multirow[t]{2}{*}{ Time of second-line CTx, months } & $<2.6$ & 13 & 1 & & & \\
\hline & $\geq 2.6$ & 13 & $0.88(0.37-2.07)$ & 0.77 & & \\
\hline
\end{tabular}

CI: Confidence interval; CTx: chemotherapy; OR: odds rate.

Efficacy. The median follow-up time was 145 days in censored cases, as of the cutoff date of March 31, 2017. In 26 patients treated with third-line CTx, the median PFS was 2.3 months, and the median OS was 5.4 months. We selected the following 17 variables for univariate analysis with regard to PFS: Age, gender, PS, location, histological type, primary lesion, P1, H1, $\mathrm{M} 1$, number of noncurative factors, irinotecan as third-line CTx, cycles of CTx, relative dose intensity, toxicity grade, serum albumin, time from first- to third-line CTx and time of second-line CTx. In univariate analysis, good PS $(0,1$; $p=0.01)$, no peritoneal metastasis $(p=0.01)$, therapy with irinotecan $(p<0.01), \geq 2$ cycles of CTx $(p<0.01)$ and high serum albumin $(\geq 3.7 \mathrm{~g} / \mathrm{dl} ; p=0.34)$ were significantly associated with longer PFS. In multivariate Cox regression analysis, irinotecan $(\mathrm{OR}=0.12,95 \% \mathrm{CI}=0.02-0.38 ; p<0.01)$ and $\geq 2$ cycles of $\mathrm{CT}(\mathrm{OR}=0.01 ; 95 \% \mathrm{CI}=0.01-0.11 ; p<0.01)$ were independent predictors of longer PFS (Table II).

Eighteen patients receiving irinotecan were assessable for response (Table III). One patient $(6 \%)$ had complete response (CR), one $(6 \%)$ had partial response, six $(33 \%)$ had stable disease, and $10(56 \%)$ had progressive disease. The ORR was $11 \%$, and the disease control rate was $44 \%$. The median number of cycles was three (range $=1-17$ ) and the RDI administered per patient was $69 \%$ (range $=24-100 \%$ ). Median PFS was 3.5 months, and median OS was 11.3 months. After discontinuing irinotecan, 10 patients $(56 \%)$ received subsequent CTx.

Adverse effects. The adverse events associated with irinotecan are shown in Table III. Ten patients $(56 \%)$ had 
Table III. Adverse events related to irinotecan in 18 patients with unresectable or recurrent gastric cancer receiving irinotecan as third-line chemotherapy.

\begin{tabular}{|c|c|c|c|c|c|c|}
\hline \multirow[b]{2}{*}{ Type } & \multicolumn{4}{|c|}{ Grade } & \multirow[b]{2}{*}{ Grade $1-4, \mathrm{n}(\%)$} & \multirow[b]{2}{*}{ Grade $3-4, \mathrm{n}(\%$} \\
\hline & 1 & 2 & 3 & 4 & & \\
\hline \multicolumn{7}{|l|}{ Hematological } \\
\hline Anemia & 7 & 8 & 3 & 0 & $18(100)$ & $3(17)$ \\
\hline Leukopenia & 2 & 5 & 2 & 1 & $10(56)$ & $3(17)$ \\
\hline Neutropenia & 2 & 4 & 1 & 4 & $11(61)$ & $5(28)$ \\
\hline Thrombocytopenia & 1 & 0 & 0 & 0 & $1(6)$ & $0(0)$ \\
\hline \multicolumn{7}{|c|}{ Laboratory test abnormalities } \\
\hline AST elevation & 3 & 1 & 3 & 0 & 7 (39) & $3(17)$ \\
\hline ALT elevation & 3 & 1 & 2 & 0 & $6(33)$ & $2(11)$ \\
\hline Bilirubin elevation & 1 & 2 & 1 & 0 & $4(22)$ & $1(6)$ \\
\hline Hyponatremia & 4 & 0 & 0 & 0 & $4(22)$ & $0(0)$ \\
\hline \multicolumn{7}{|l|}{ Non-hematological } \\
\hline Nausea & 6 & 3 & 1 & 0 & $10(56)$ & $0(0)$ \\
\hline Vomiting & 4 & 1 & 0 & 0 & $5(28)$ & $0(0)$ \\
\hline Anorexia & 3 & 3 & 1 & 0 & $7(39)$ & $1(6)$ \\
\hline Diarrhea & 5 & 3 & 1 & 0 & $9(50)$ & $1(6)$ \\
\hline Fatigue & 4 & 3 & 0 & 0 & $7(39)$ & $0(0)$ \\
\hline Febrile neutropenia & - & - & 2 & 0 & $2(11)$ & $2(11)$ \\
\hline Alopecia & 3 & 0 & - & - & $3(17)$ & - \\
\hline
\end{tabular}

AST: Aspartate aminotransferase; ALT: alanine aminotransferase.

grade 3 or 4 toxicities and these were managed well. The most frequent hematological grade 3 or 4 toxicities were neutropenia (28\%), leukopenia (17\%) and anemia (17\%). Grade 3 or 4 non-hematological toxicities were nausea $(6 \%)$, anorexia (6\%), diarrhea (6\%) and febrile neutropenia (11\%). Two patients $(11 \%)$ died of disease progression within 30 days of the last administration of irinotecan. No treatmentrelated death occurred.

\section{Discussion}

Despite the lack of evidence of survival benefit of third-line CTx, two retrospective studies have been reported about the outcome of irinotecan as third-line CTx for patients with unresectable or recurrent GC refractory to fluoropyrimidines, platinum and taxanes. In results, irinotecan produced an ORR of $3-18 \%$, median PFS of 2.2-2.3 months and median OS of 4.0-6.0 months for advanced GC in the third-line setting $(14,15)$. Our data indicate that irinotecan as thirdline CTx gave an ORR of $11 \%$, a median PFS of 3.5 months and OS of 11.3 months, comparable to those two studies. Additionally, in the phase-III WJOG4007 trial, irinotecan as second-line CTx produced a 14\% ORR, a median PFS of 2.3 months and OS of 8.4 months (11). Based on these findings, irinotecan may be a clinically effective drug for third-line therapy for selective patients with unresectable or recurrent GC. However, the prolonged OS in this study might be attributed to the higher proportion of patients $(10 ; 56 \%)$ who underwent four or more lines of CTx, compared with the proportion of $21-40 \%$ in the two former studies.

Some studies reported on favorable predictors affecting survival following third-line CTx $(4,21)$. A good PS, high serum albumin, low histological grade, an increased number of noncurative factors, a long time from first- to third-line CTx and a long time of second-line CTx were independent predictors for better survival in multivariate analysis. In this study, irinotecan and increasing number of treatment cycles of third-line CTx were independent predictors of longer PFS in multivariate analysis. However, two patients $(11 \%)$ died of disease progression within 30 days of the final dosage of irinotecan, although no treatment-related death occurred. Thus, the careful selection of patients who are suitable for irinotecan as third-line setting seems to be required, while irinotecan therapy may be regarded as an available option in third-line setting to prolong PFS by increasing the number of treatment cycles.

In this study, the most frequent grade 3 or 4 toxicities caused by irinotecan were neutropenia (28\%), leukopenia (17\%) and anemia (17\%), with $11 \%$ developing febrile neutropenia. The most common grade 3 or 4 nonhematological toxicities were nausea $(6 \%)$, anorexia $(6 \%)$ and diarrhea $(6 \%)$. These incidences of grade 3 or 4 toxicities were not very different from those in previous studies of irinotecan as second-line or third-line CTx (3, 4, $11,14,15)$, indicating the safety of irinotecan in the thirdline setting. However, 16 patients (89\%) needed dose reduction or delays of irinotecan, with lower RDI of $69 \%$ in 
this study compared with that of $77-78 \%$ in two previous studies $(14,15)$. By these findings, it is suggested that the appropriate dose or delays of irinotecan should be based on the patient's condition.

\section{Conclusion}

In conclusion, irinotecan therapy may become optimal and tolerated in the third-line setting to prevent disease progression for selective patients with unresectable or recurrent GC refractory to fluoropyrimidines with or without platinum and taxanes, by increasing the number of treatment cycles, even if requiring dose reductions or delays. Although the current retrospective study was performed at a single center on a limited patient population, and was therefore subject to selection bias, our findings should stimulate further inquiry into how to manage in these patients treated with irinotecan as third-line CTx.

\section{Conflicts of Interest}

Minoru Fukuchi and the other co-authors have no conflicts of interest in regard to this study.

\section{Authors' Contributions}

MF, KK and TI collected clinical information and performed statistical analysis. MF, YK, KI, EM and HI designed the study protocol and wrote the article.

\section{References}

1 Ferlay J, Soerjomataram I, Dikshit R, Eser S, Mathers C, Rebelo M, Parkin DM, Forman D and Bray F: Cancer incidence and mortality worldwide: Sources, methods and major patterns in GLOBOCAN 2012. Int J Cancer 136: E359-386, 2015. PMID: 25220842. DOI: $10.1002 / \mathrm{ijc} .29210$

2 Koizumi W, Narahara H, Hara T, Takagane A, Akiya T, Takagi M, Miyashita K, Nishizaki T, Kobayashi O, Takiyama W, Toh Y, Nagaie T, Takagi S, Yamamura Y, Yanaoka K, Orita $\mathrm{H}$ and Takeuchi M: S-1 plus cisplatin versus S-1 alone for first-line treatment of advanced gastric cancer (SPIRITS trial): A phase III trial. Lancet Oncol 9: 215-221, 2008. PMID: 18282805. DOI: 10.1016/S1470-2045(08)70035-4

3 Thuss-Patience PC, Kretzschmar A, Bichev D, Deist T, Hinke A, Breithaupt K, Dogan Y, Gebauer B, Schumacher G, Reichardt PThuss-Patience PC, Kretzschmar A and Bichev D: Survival advantage for irinotecan versus best supportive care as secondline chemotherapy in gastric cancer-A randomised phase III study of the Arbeitsgemeinschaft Internistische Onkologie (AIO). Eur J Cancer 47: 2306-2314, 2011. PMID: 21742485 DOI: 10.1016/j.ejca.2011.06.002

4 Kang JH, Lee SI, Lim DH, Park KW, Oh SY, Kwon HC, Hwang IG, Lee SC, Nam E, Shin DB, Lee J, Park JO, Park YS and Lim HY: Salvage chemotherapy for pretreated gastric cancer: A randomized phase III trial comparing chemotherapy plus best supportive care with best supportive care alone. J Clin Oncol 30:
1513-1518, 2012. PMID: 22412140. DOI: 10.1200/JCO. 2011.39.4585

5 Ford HE, Marshall A, Bridgewater JA, Janowitz T, Coxon FY, Wadsley J, Mansoor W, Fyfe D, Madhusudan S, Middleton GW, Swinson D, Falk S, Chau I, Cunningham D, Kareclas P, Cook N, Blazeby JM and Dunn JA: Docetaxel versus active symptom control for refractory oesophagogastric adenocarcinoma (COUGAR-02): An open-label, phase 3 randomised controlled trial. Lancet Oncol 15: 78-86, 2014. PMID: 24332238. DOI: 10.1016/S1470-2045(13)70549-7

6 Hironaka S, Zenda S, Boku N, Fukutomi A, Yoshino T and Onozawa Y: Weekly paclitaxel as second-line chemotherapy for advanced or recurrent gastric cancer. Gastric Cancer 9: 14-18, 2006. PMID: 16557431. DOI: 10.1007/s10120-005-0351-6

7 Kodera Y, Ito S, Mochizuki Y, Fujitake S, Koshikawa K, Kanyama Y, Matsui T, Kojima H, Takase T, Ohashi N, Fujiwara M, Sakamoto J and Akimasa N: A phase II study of weekly paclitaxel as second-line chemotherapy for advanced gastric Cancer (CCOG0302 study). Anticancer Res 27: 2667-2671, 2007. PMID: 17695430.

8 Matsuda G, Kunisaki C, Makino H, Fukahori M, Kimura J, Sato T, Oshima T, Nagano Y, Fuii S, Takagawa R, Kosaka T, Ono HA, Akiyama $\mathrm{H}$ and Ichikawa Y: Phase II study of weekly paclitaxel as a second-line treatment for S-1-refractory advanced gastric cancer. Anticancer Res 29: 2863-2867, 2009. PMID: 1959697.

9 Sasaki Y, Nishina T, Yasui H, Goto M, Muro K, Tsuji A, Koizumi W, Toh Y, Hara T and Miyata Y: Phase II trial of nanoparticle albumin-bound paclitaxel as second-line chemotherapy for unresectable or recurrent gastric cancer. Cancer Sci 105: 812-817, 2014. PMID: 24716542. DOI: $10.1111 /$ cas.12419

10 Fukuchi M, Mochiki E, Ishiguro T, Ogura T, Sobajima J, Kumagai Y, Ishibashi K and Ishida H: Efficacy of nab-paclitaxel as second-line chemotherapy for unresectable or recurrent gastric cancer. Anticancer Res 36: 6699-6703, 2016. PMID: 27920005. DOI: 10.21873 anticanres.11281

11 Hironaka S, Ueda S, Yasui H, Nishina T, Tsuda M, Tsumura T, Sugimoto N, Shimodaira H, Tokunaga S, Moriwaki T, Esaki T, Nagase M, Fujitani K, Yamaguchi K, Ura T, Hamamoto Y, Morita $\mathrm{S}$, Okamoto I, Boku N and Hyodo I: Randomized, open-label, phase III study comparing irinotecan with paclitaxel in patients with advanced gastric cancer without severe peritoneal metastasis after failure of prior combination chemotherapy using fluoropyrimidine plus platinum: WJOG 4007 trial. J Clin Oncol 31: 4438-4444, 2013. PMID: 24190112. DOI: 10.1200/JCO. 2012.48.5805

12 Wilke H, Muro K, Van Cutsem E, Oh SC, Bodoky G, Shimada Y, Hironaka S, Sugimoto N, Lipatov O, Kim TY, Cunningham D, Rougier P, Komatsu Y, Ajani J, Emig M, Carlesi R, Ferry D, Chandrawansa K, Schwartz JD and Ohtsu A: Ramucirumab plus paclitaxel versus placebo plus paclitaxel in patients with previously treated advanced gastric or gastro-oesophageal junction adenocarcinoma (RAINBOW): A double-blind, randomised phase 3 trial. Lancet Oncol 15: 1224-1235, 2014. PMID: 25240821. DOI: 10.1016/S1470-2045(14)70420-6

13 Shitara K, Matsuo K, Mizota A, Kondo C, Nomura M, Takahari D, Yokota T, Ura T, Ito S, Sawaki A, Tajika M, Kawai H and Muro K: Association of fluoropyrimidines, platinum agents, taxanes, and irinotecan in any line of chemotherapy with survival in patients with advanced gastric cancer. Gastric Cancer 
14: 155-160, 2011. PMID: 21340668. DOI: 10.1007/s10120011-0019-3

14 Kawakami T, Machida N, Yasui H, Kawahira M, Kawai S, Kito Y, Yoshida Y, Hamauchi S, Tsushima T, Todaka A, Yokota T, Yamazaki K, Fukutomi A and Onozawa Y: Efficacy and safety of irinotecan monotherapy as third-line treatment for advanced gastric cancer. Cancer Chemother Pharmacol 78: 809-814, 2016. PMID: 27566700. DOI: 10.1007/s00280-016-3138-z

15 See comment in PubMed Commons belowNishimura T, Iwasa S, Nagashima K, Okita N, Takashima A, Honma Y, Kato K, Hamaguchi T, Yamada Y, Shimada Y and Boku N: Irinotecan monotherapy as third-line treatment for advanced gastric cancer refractory to fluoropyrimidines, platinum, and taxanes. Gastric Cancer 20: 655-662, 2017. PMID: 27858180. DOI: $10.1007 /$ s10120-016-0670-9

16 Sobin LH, Gospodarowicz MK and Wittekind $\mathrm{CH}$ : TNM Classification of Malignant Tumours. Seven Edition. Oxford: Wiley-Blackwell, 2009.

17 Japanese Gastric Cancer Association: Japanese classification of gastric carcinoma: Third English edition. Gastric Cancer 14: 101-112, 2011. PMID: 21573743. DOI: 10.1007/s10120-0110041-5

18 Futatsuki K, Wakui A, Nakao I, Sakata Y, Kambe M, Shimada Y, Yoshino M, Taguchi T and Ogawa N: Late phase II study of irinotecan hydrochloride (CPT-11) in advanced gastric cancer. CPT-11 Gastrointestinal Cancer Study Group. Gan To Kagaku Ryoho 21: 1033-1038, 1994. PMID: 8210254.
19 Eisenhauer EA, Therasse P, Bogaerts J, Schwartz LH, Sargent D, Ford R, Dancey J, Arbuck S, Gwyther S, Mooney M, Rubinstein L, Shankar L, Dodd L, Kaplan R, Lacombe D and Verweij J: New response evaluation criteria in solid tumours: Revised RECIST guideline (version 1.1). Eur J Cancer 45: 228247, 2009. PMID: 19097774. DOI: 10.1016/j.ejca.2008.10.026

20 Cancer Therapy Evaluation Program: Common Terminology Criteria for Adverse Events v4.03. 2009. Available at: http://ctep.cancer.gov/protocolDevelopment/electronic_applicatio ns/ctc.htm\#ctc_40.

21 Shim HJ, Yun JY, Hwang JE, Bae WK, Cho SH and Chung IJ: Prognostic factor analysis of third-line chemotherapy in patients with advanced gastric cancer. Gastric Cancer 14: 249-256, 2011. PMID: 21431297. DOI: 10.1007/s10120-011-0032-6
Received November 15, 2019

Revised December 1, 2019

Accepted December 3, 2019 